\title{
The Professional Logic of Sustainability Managers: Finding Underlying Dynamics
}

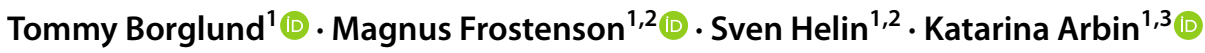

Received: 27 April 2020 / Accepted: 7 November 2021 / Published online: 25 December 2021

(C) The Author(s) 2021

\begin{abstract}
The role of the Sustainability Manager (SM) is expanding. Whether SMs are turning into a new profession is under debate. Pointing to the need for a distinct professional logic to qualify as a profession, we identify what is contained within a professional logic of SMs. Through analyzing ambiguities present in the role of the SMs, we show that there is no specific distinct professional logic of SMs, but rather a meta-construct building on market, bureaucratic, and sustainability logics. In addition, we point to the complex configurations of and relationships between these underlying logics. The complexities also explain why the SMs differ from traditional professions and why it is problematic to talk about a 'SM profession'. Rather, SMs are 'organizational professionals'. The article builds on 21 interviews with SMs working for Swedish companies.
\end{abstract}

Keywords Institutional logics $\cdot$ Profession $\cdot$ Sustainability $\cdot$ Sustainability manager $\cdot$ Sweden

\section{Introduction}

In recent years, the role of the Sustainability Manager (SM), ${ }^{1}$ denoting the most senior position within the organization with responsibility for sustainability issues, has been introduced in companies, reflecting the expansion of CSR and sustainability in business (Wright et al., 2012; Strand, 2013, 2014; Miller \& Serafeim, 2014; Borglund et al., 2017; Carollo \& Guerci, 2018). Commonly, SMs have the prime responsibility to oversee the company's sustainability strategy, its implementation, and results (cf. Kanashiro \& Rivera, 2019; Strand, 2013, 2014). They may or may not be part

Tommy Borglund

tommy.borglund@oru.se

Magnus Frostenson

magnus.frostenson@oru.se; magnus.frostenson@hiof.no

Sven Helin

sven.helin@oru.se; sven.helin@hiof.no

Katarina Arbin

katarina.arbin@oru.se

1 Örebro University School of Business, SE-701 82 Örebro, Sweden

2 Østfold University College, P.O. Box 700, NO-1757 Halden, Norway

3 Department of Business and Economic Studies, University of Gävle, SE-801 76 Gävle, Sweden of the top management team (TMT), but are the ones that occupy the highest position in the company with specific responsibility for sustainability (Carollo \& Guerci, 2018). The number of SMs and their influence have increased over the years, with a breakthrough in the early 2000's (Acre, 2011; GreenBiz, 2018; Weinreb Group, 2014, 2018). GreenBiz (2018, p. 15) showed that 89 percent of surveyed international companies with revenues greater than $\$ 1$ billion have an executive "working $100 \%$ on sustainability". According to the same study, 44 percent of the persons heading the sustainability work had the title vice president or senior vice president.

\footnotetext{
${ }^{1}$ In this paper, we use the term Sustainability Manager (SM) to denote the most senior position within the organization with responsibility for sustainability issues, in line with Guerci and Pedrini (2014) and Carollo and Guerci (2018). Other titles or concepts are also used in the literature, for example Chief Sustainability Officers (CSOs, see Acre, 2011; Weinreb Group, 2011, 2014, 2018; Strand, 2013, 2014; Miller \& Serafeim, 2014; Peters \& Romi, 2014; Kanashiro \& Rivera, 2019; Peters et al., 2019; Fu et al., 2020), Corporate Social Responsibility (CSR) Managers (Risi \& Wickert, 2017), Chief Officers of CSR (Strand, 2013), and in some cases also CSR practitioners (Brès et al., 2019). SMs may but need not be part of the top management team (TMT). In this study, all interviewees are the most senior persons responsible for sustainability issues in the companies, although not necessarily part of the TMT. The positions and methodological considerations related to these positions are discussed in the methodology section. Notably, some scholars use other concepts in the same way as we use SMs: "CSOs as all people with primary responsibility for sustainability in an organization even if their title is not CSO but a vice president or a director" (Miller \& Serafeim, 2014, p. 201).
} 
SMs focus on many issues connected to economic, social, and environmental responsibility, including ethical issues in the organization (Borglund et al., 2017). Activities that may be connected to SM responsibility may include, for example, mergers and acquisitions, product development, financing, cost savings, product life cycle analyses, partnerships, and stakeholder engagement (Acre, 2011). Frequently, they become a link between the company and its stakeholders, enacting boundary-spanning functions related to governance, systems, networking, collaboration, interdependency, and experimentation (Johnstone, 2019). Externally, SMs are important actors within the CSR discourse, along with investors, NGOs, consultants, and business schools. Necessary skills include strategy, HR knowledge, communication, commercial thinking, and policy engagement, also showing the broad potential scope of SM work (Acre, 2011).

Reasons for appointing SMs have been discussed, including improved reputation by sending signals to stakeholders about commitment to CSR, an increased ability to integrate CSR in the organization, increased understanding of CSR in the TMT, as well as increasing the efficiency of CSR implementation (Wiengarten et al., 2017). Also, when it comes to sustainability there is sometimes an external language gap between companies and investors that needs to be bridged (O’Neill 2016).

As companies become more advanced and strategic in terms of CSR, the same goes for the role of the SM (Miller $\&$ Serafeim, 2014), which becomes more senior and connected to the overall business strategy (Vallentin \& Spence, 2017). Aligning internal and external sustainability strategy is a task (Eccles \& Krzus, 2015), for example, relating business and sustainability to Shared Value (Porter \& Kramer, 2006, 2011).

The noticeable development of SMs as a professional group has led scholars to problematize their role(s) in various ways. Functional aspects, for example how sustainability leadership could and should be provided in response to stakeholder concerns, have been highlighted (Peters et al., 2019), as well as their concrete role in organizations, including interaction with shareholders (Miller \& Serafeim, 2014). Structural aspects include discussions on relevant positions in the organization, for example closeness to the TMT, the role of sustainability committees to the Board of Directors, or the issue of centralization or decentralization of sustainability issues in the organization, as the company becomes more mature with regard to sustainability. It has also been discussed whether the SM role will disappear once the company gets 'truly sustainable' (Strand, 2014). Reflecting this, Risi and Wickert (2017) claim that the more integrated, the more transformed the role gets. There may be a diminishing importance of such managers over time as CSR becomes institutionalized in the company (Bondy et al., 2012). However, to some extent, new sustainability issues emerge as well as new types of responsibilities that give SMs new important tasks to carry out (Risi \& Wickert, 2017). Others focus on personal background aspects and how such factors come into play (Peters et al., 2019; Strand, 2014; Wiengarten et al., 2017). Performance implications have also been studied (e.g., Fu et al., 2020; Kanashiro \& Rivera, 2019; Peters et al., 2019). Wiengarten et al. (2017), for example, find that in some situations there is a positive correlation between the role and financial performance. Another strand of the literature points to the relationship between SMs and performance as conditioned by SM characteristics, earlier sustainability record, time, and environmental regulation (Kanashiro \& Rivera, 2019; Peters et al., 2019). Some scholars have discussed practical problems relating to the role, for example tensions with other internal constituents (Jutterström \& Norberg, 2013; Risi \& Wickert, 2017).

Yet others, however fewer, have been more interested in the way SMs reason, think, and feel within business organizations, for example from an identity perspective, emphasizing the complicated identity struggles of inhabiting the role (Carollo \& Guerci, 2018; Wright et al., 2012). Discussions on whether and how SMs (or CSR practitioners) are forming a new profession have also been published (Brès et al., 2019). Even if no definitive answer has been given to the question of whether there is a new SM profession or (if so) what it is constituted of, relevant aspects have been touched upon. To understand the underlying aspects of the SM role in organizations, it is obvious that one also has to identify underlying claims, demands, expectations, clashes, and struggles that relate to the role. But despite identity-related studies (Carollo \& Guerci, 2018; Risi \& Wickert, 2017; Wright et al., 2012), pointing to underlying clashes between business and sustainability values, confusing the identities of SMs, we know relatively little about the underlying nature of the logic that guides SMs in their work. In particular, it is of importance to identify what is actually contained within the professional logic of SMs, as it is central to understand what it is that is action-guiding within the profession, expressing the ethos, norms, beliefs, and values of SMs. The purpose of the article, thus, is to identify the professional logic of SMs. Its specific research question is: What is contained within a professional logic of Sustainability Managers? By that we refer to the beliefs and action-guiding principles that tend to shape the cognitions and behaviors of SMs in their professional role (cf. Dunn \& Ross, 2010).

We proceed with this task by identifying underlying ambiguities within the role, reflecting three distinct logics-relating to sustainability, market, and bureaucracy - that either clash, mix, or can be seen as unclear or balanced, constituting a complex content of a professional logic of SMs. Thus, rather than finding an unequivocal professional logic, we identify the dynamics of the professional logic of SMs and show that it does not 'exist on its own' (in contradistinction 
to the logics of doctors, lawyers, and similar occupational groups), but is constituted by other logics that relate to each other in various ways. As the study will show, the SM role is so strongly conditioned by the organizational realities and priorities of business, from which the very role emanates, that the logic becomes vague and difficult to define qua professional in a more independent sense.

The article is empirical, building on interviews with SMs of national and international companies of Swedish origin. The next section offers a theoretical background to the issue of professional logics. The methodology section then follows, after which the empirics contain the identified professional ambiguities. A concluding discussion finalizes the article.

\section{A Professional Logic of Sustainability Managers?}

A relatively recent phenomenon in the literature is an increased interest in the professional aspects of the SM role (Brès et al., 2019). A profession can be seen as a specific and to some degree an autonomous social system where professionals compete with each other for influence (Abbott, 1988). Historically, the role of the professions has been strong. Scholars within institutional theory have pointed out that professions are drivers increased homogenization of organizational fields and societal spheres (DiMaggio \& Powell, 1983). They functions as influential crafters of institutions in modern society (Muzio et al., 2013; Scott, 2008). Although subject to profound changes, professions have had leading roles when it comes to the creation and tending of institutions (Muzio et al., 2013; Scott, 2008). The traditionally strong role of the professions has also turned professionalization into an attractive option for occupational groups that have not enjoyed status or recognition. Professionalization involves an ambition to control a market of expertise, a striving for social status and upward social mobility (Larson, 1978).

To Evetts (1999), a profession is based on higher education and training, often tied to the middle class in society and within the service sector. Most definitions emphasize the connection to formal higher education, mainly at universities. Academic education provides a higher, abstract and adaptable way of learning, leading to new forms of knowledge and skills different from the old ones (Parsons, 1964). Freidson (1999) describes a profession as an ideal type with a number of components; publicly recognized knowledge grounded in abstract concepts and theories, a defined division of labor within the profession, control of the job market through merit systems and licensing and control of the education through universities. Others see professions as discursive categories (Evetts, 2003; Fournier, 1999), reflecting a "linguistic resource that occupations claim for themselves" (Brès et al., 2019, p. 253).

Relating this background to SMs reveals interesting patterns. There is a developing abstract field of academic CSR or sustainability knowledge (Painter-Morland et al., 2015). SMs increasingly share a common language, for example of expert terms developed within the discourse of sustainability, singling out the SM role as a discursive category (Brès et al., 2019; Evetts, 2003; Fournier, 1999). However, despite the connection to higher education, knowledge is relatively scattered without formal controls or specific admittance requirements (Freidson, 1999). Even though there are many network organizations in the field, few if any formal requirements apply for membership. The network organizations do not hold formal power over its members and there is no strong joint professional code of ethics for SMs. Thus, it can be argued that SMs lack the requisite similar education backgrounds and knowledge bases. What unites them is, rather, that they tend to share common values and a common vision of making business more sustainable (Brès et al., 2019). Sharing common values, a common identity, a higher ambition and a shared purpose of "serving the common good" is congruent with descriptions of traits of a profession (e.g., Parsons, 1964; Larson, 1978; Abbot, 1988; Freidson, 1999; Evetts, 2003).

SMs share many aspects with relatively recently developed occupations such as HR managers, Chief Information Officers, Communication or Quality Managers (Bailey, 2011, 2015; Elg et al., 2011; Martin et al., 2019; Rucci, 1997; Ulrich et al., 2013; Waddell \& Mallen, 2001). A Quality Manager, for example, shares some of the work content of a SM such as environmental responsibility and other CSR issues (Elg et al., 2011). However, Martin et al. (2019) claim that quality management lacks unifying professional prerequisites, and that labels such as practitioners (rather than professionals) should be used. HR managers seem to have more marked traits of a profession (Bailey, 2011, 2015; Ulrich et al., 2013). There is a joint knowledge base with educational programs at universities for HR managers, giving students a degree and 'license' in HR, as well as strong professional associations, policies, regulation, ethical guidelines and codes of conduct. The HR field is also close to CSR in some aspects, and many times, HR managers and SMs work together on enhancing sustainability, even though also with some tensions connected to division of responsibility and influence between the two (Gond et al., 2011; Guerci \& Pedrini, 2014).

Analytically, Freidson (2001) has contributed by pointing to three logics that are situated within the organizational context, determining what members of the organization do and how they do it, namely the professional logic, the market logic, and the bureaucratic logic. These different logics 
explain who or 'what' it is that controls and guides actions and decisions within the professional context. The professional logic is fundamental to how professionals think of and understand their work, with regard to, for example, control, governance, strategy, and authority structures (cf. Thornton, 2002). A professional logic frames the occupational context and guides not only how to think about work as such, but also, from an identity perspective, who I am as a professional in relation to colleagues and others (cf. Carollo \& Guerci, 2018). What is particular about a professional logic is not just an understanding of how to perform work, but also an idea of the purpose of the profession and what it should bring about, for example to work in the public interest. In contrast, the market logic allows decisions, understandings, and so on, to be dependent on customers, clients and other groups and their interests. Guided by the market logic, the very rationale of how to perform and organize work becomes different. The bureaucratic logic, in turn, has rules, policies, guidelines, et cetera within the hierarchical organization as the guiding principle of organizing work. In its essence, it is highly managerial, relying on rules and formal mandates.

All these logics can be understood as institutional (Friedland \& Alford, 1991), in the sense that they exist on an overarching societal level, as normative understandings of how issues should be understood, organized and effectuated. They are "cultural beliefs and rules that shape the cognitions and behaviors of actors" (Dunn \& Jones, 2010, p. 114). They also matter in specific contexts, such as the professional one, as action-guiding normative beliefs that bring about certain interpretations of reality (cf. Friedland $\&$ Alford, 1991). Thus, these logics reflect broader cultural templates that provide organizational members with meansends designations (Pache \& Santos, 2010). Such logics exist at the overarching, societal level (Herremans et al., 2009), but are enacted (consciously or not) by individual actors within organizations.

However, in relation to these logics, the role of the SM distinguishes itself from other professional groups in at least two ways. Firstly, the very existence of the SM is warranted by the increased awareness of sustainability and responsibility as an overwhelming trend in business, which can also change the way we think about professions in general (Brès et al., 2019). The existence of SMs, one could argue, is a corporate response to the (institutional) logic of and pressure for sustainability, inherent in society (Bondy et al., 2012; Frostenson \& Helin, 2017; Risi \& Wickert, 2017). Sustainability contextualizes the role of the corporation in relation to environmental and societal needs and priorities. The sustainability logic tends to guide behaviors characterized by concerns for issues such as social justice and environmental preservation (Kok et al., 2019) but stands in at least potential contradistinction to the logic of the market that places its own demands on what the SMs are supposed to achieve. In other words, there is a further logic compared to the ones put forward by Freidson (2001) that warrants attention. In practice, a professional logic is often contrasted with market or bureaucratic logics (Freidson, 2001), but in relation to SMs, the sustainability logic is also relevant to understand in the professional context, in relation to tensions within the profession.

It has been suggested (e.g., Carollo \& Guerci, 2018) that tensions that SMs experience can, at least partly, be ascribed to the underlying conflict of business (market logic) vs. values (sustainability logic). Such an underlying (potential) clash of several logics is one aspect that makes the case of SMs special. That is not to deny that concepts have been developed that try to bridge such clashes strategically and in a more practical sense (e.g., through Created Shared Value, see Porter \& Kramer, 2011). But the point is that the underlying values and priorities of professionals may imply differing and sometimes contrasting ways of comprehending and dealing with specific professional situations. Many studies of professionals in accounting, medicine, teaching, and other disciplines point to an ongoing challenge to the traditional professions (e.g., Evetts, 2003; Greenwood \& Lachman, 1996). This challenge comes about through market reforms, management ideas, et cetera., that infuse market logic into professional thinking. The market logic operates through the motivation to achieve competitive advantage, efficiency and profit, implying that behavior is economically motivated (see e.g., Kok et al., 2019). Such an 'external' logic challenges the traditional professional understanding of how things should be done and controlled (Pache \& Santos, 2010). Instability, fragility, tensions, and uncertainty may follow, since different logics tend to prescribe different understandings of the task at hand, and consequently, different actions (cf. Hayes \& Rajão, 2011). From an identity perspective, making sense of conflicting logics in a professional context is problematic (Bévort \& Suddaby, 2016). Professional logic may also be challenged by bureaucratic logic (Freidson, 2001), implying that, for example, managerially initiated rules, routines, and structures become the fundamental organizing principles of professional work (rather than letting the professionals decide).

Secondly, being a new profession, or possibly a profession under development, SMs only partially relate to such a background-where the traditionally strong professional logic of a certain professional group is challenged by other logics, for example the market logic as a consequence of market reforms affecting the professional space. Unlike traditional professions, there is a vagueness of the professional logic of SMs. This is also reflected in the literature, where clear definitions or identifications of it are lacking (Brès et al., 2019) or only partially and dichotomously defined (as a business vs. values conflict), as underlying reasons for tensions in the role (Carollo \& Guerci, 2018). Pointing more specifically 
to Carollo and Guerci (2018), they identify three tensions, relating to a business orientation vs. values orientation, an insider-outsider perspective, and a short-term vs. long-term view. The first underlying conflict concerns an aspect of logics, the clash between sustainability and market logics, which seems to be an inherent fundamental dichotomy of the role.

Going deeper into the underlying logics of the role, thus, is a clue to understanding professionalism among SMs-and their possibilities to become a 'real' profession in the sense of having their own principles and coherent understandings of how to perform the profession, necessary education, specific knowledge authority of the field, controlling the standards of good performance, et cetera. Judging from earlier literature, some advances have been made, but less relating to logics and more to identity, the issue of who the SM is and what is central, distinguishable and enduring about the role (cf. Albert \& Whetten, 1985). Apart from Carollo and Guerci (2018), another example is Wright et al. (2012), who argue that balancing or bridging tensions comes about through enacting key identities, the 'green change agent', the 'rational manager', and the 'committed activist'. In their lives and professional roles, SMs must balance contradictions between their own senses of self and other relevant work and non-work contexts that they belong to (Wright et al., 2012).

The corollary of previous reasoning is that we do not only see potential clashes of logics within the SM profession, but also a vagueness of the professional logic of SMs, along with a relatively underdetermined understanding of which underlying logics that constitute or undergird it-and in which way. One could reasonably ask what this professional logic consists of - or whether there is one at all. As we see it, it is an empirical task to identify such a logic. Given the vagueness of the professional logic and the underlying frictions between potentially different underlying logics, the predicament of the profession is hardly the same as, for example, accountants or medical doctors, where typical challenges of a traditional professional logic exist. Although current literature has pointed to the conflict between sustainability and market logics in relation to SMs, nothing precludes further logics to be conditioning the SM profession, for example the bureaucratic logic or others. Given this background, a deeper empirical understanding is of want. The remaining parts of this article will be devoted to providing a deeper understanding of the professional logic of SMs.

\section{Method}

The study follows the stream of research on professional logics and professional identity work (cf. Freidson, 2001). Like other studies, we base our empirical material on semi-structured in-depth interviews to make sense of the situations that SMs face (Carollo \& Guerci, 2018; Kok et al., 2019; Wright et al., 2012).

For the study, 21 SMs working in Sweden were interviewed. A criterion for selecting the respondents was that $\mathrm{s} /$ he had a position as a SM in a large or medium-sized company, being the most senior person responsible for sustainability in the organization. From a research design perspective, finding the highest ranking manager with responsibility for sustainability was central for qualifying as an interview person in our study. That excluded, for example, respondents with only partial responsibility for sustainability in their positions. Hence, we were interested in the highest ranking executives ('C-suite') or persons with responsibility for sustainability in close connection to the TMT, in line with the discussion on "Upper echelons" (Hambrick \& Mason, 1984). The TMT contains a smaller group of executives in the top of the organization with an overall responsibility (Hambrick \& Mason, 1984; Mintzberg, 1979; Strand, 2013). Some of the SMs were in the TMT and hence could be labeled CSOs (Strand, 2014). Others were just outside the TMT, but had access to TMT meetings when needed. The closeness to the TMT was also something discussed by the SMs themselves as an issue related to the possibility to exercise SM work, as we will see in the next section.

As can be seen from Table 1, five of the 21 respondents were in the TMT, whereas 13 were just outside the TMT, reporting to a TMT executive. In addition, three managers were on organizational level 3. This reflects that the most common position among Swedish SMs is to be just outside the TMT on management layer 2.

Access to respondents was possible through professional networks for SMs. All of them work in the Swedish context, but several are employed by international companies. That is, their work is not limited to Sweden and contains international supply chain issues and other tasks. The focus on Swedish SMs is reasonable considering their increasingly stronger role in Swedish companies and the developed job market within sustainability in Scandinavia. The Scandinavian countries are often perceived as advanced when it comes to sustainability (De Geer et al., 2009; Jutterström \& Norberg, 2013; Strand et al., 2015; Borglund et al., 2017). The respondents differ in terms of gender, managerial level, title of the position, role seniority and industry (Carollo \& Guerci, 2018), see Table 1. In Table 1, management layer 1 represents a position in the TMT, 2 represents a SM that reports to a TMT member, and management layer 3 represents two hiererchial levels below the TMT.

From July 2018 to October 2019, the 21 interviews were carried out by one of the researchers, lasting for 30-60 min. The interviews were made mainly in person but in some cases over telephone, depending on the availability of the interview person. They were guided by about ten open-ended 
Table 1 Participating sustainability managers (companies)

\begin{tabular}{|c|c|c|c|c|c|c|}
\hline Name & Male/Female & $\begin{array}{l}\text { Role } \\
\text { seniority } \\
\text { (years) }\end{array}$ & $\begin{array}{l}\text { Mgmt layer; } \\
\text { closeness to } \\
\text { TMT }\end{array}$ & Title & Organizational unit & Business/industry \\
\hline A & $\mathrm{F}$ & $10-15$ & 2 & SVP & Sustainability & $\begin{array}{l}\text { Large global construction company, } \\
\text { publically listed }\end{array}$ \\
\hline B & $\mathrm{F}$ & $10-15$ & 1 & Manager & Sustainability & $\begin{array}{l}\text { Large national privately owned } \\
\text { retailer }\end{array}$ \\
\hline $\mathrm{C}$ & $\mathrm{F}$ & $5-10$ & 1 & Head of & Communication and sustainability & $\begin{array}{l}\text { Large national privately owned } \\
\text { construction company }\end{array}$ \\
\hline $\mathrm{D}$ & $\mathrm{F}$ & $5-10$ & 2 & Director & Sustainability & $\begin{array}{l}\text { Larger national real estate company, } \\
\text { privately owned }\end{array}$ \\
\hline $\mathrm{E}$ & M & $3-5$ & 3 & Head of & Sustainability & $\begin{array}{l}\text { Large international bank, publically } \\
\text { listed }\end{array}$ \\
\hline $\mathrm{F}$ & $\mathrm{F}$ & $5-10$ & 2 & Manager & Sustainability & $\begin{array}{l}\text { Large international privately owned } \\
\text { recycling company }\end{array}$ \\
\hline G & $\mathrm{F}$ & $3-5$ & 2 & Head of & Sustainability & $\begin{array}{l}\text { Medium-sized national construction } \\
\text { and real estate company, privately } \\
\text { owned }\end{array}$ \\
\hline $\mathrm{H}$ & $\mathrm{F}$ & $3-5$ & 2 & Head of & Sustainability & $\begin{array}{l}\text { Medium-sized national supplier } \\
\text { construction sector, publically } \\
\text { listed }\end{array}$ \\
\hline I & M & $3-5$ & 3 & Head of & Sustainability & $\begin{array}{l}\text { Large global telecom company, } \\
\text { publically listed }\end{array}$ \\
\hline $\mathrm{J}$ & $\mathrm{F}$ & $5-10$ & 2 & Head of & Sustainability and quality & $\begin{array}{l}\text { Large global telecom company, } \\
\text { publically listed }\end{array}$ \\
\hline K & $\mathrm{F}$ & $5-10$ & 2 & Head of & Communication and sustainability & $\begin{array}{l}\text { National privately owned brewery } \\
\text { and hospitality company }\end{array}$ \\
\hline $\mathrm{L}$ & $\mathrm{F}$ & $3-5$ & 2 & Head of & Sustainability & $\begin{array}{l}\text { Large international retailer, pri- } \\
\text { vately owned }\end{array}$ \\
\hline M & M & $10-15$ & 2 & Head of & Sustainability & $\begin{array}{l}\text { Medium-sized national bank, pri- } \\
\text { vately owned }\end{array}$ \\
\hline $\mathrm{N}$ & M & $3-5$ & 2 & Head of & Sustainability & $\begin{array}{l}\text { Large international transportation } \\
\text { company, privately owned }\end{array}$ \\
\hline $\mathrm{O}$ & $\mathrm{F}$ & $3-5$ & 3 & Head of & Marketing and CSR & $\begin{array}{l}\text { Medium-sized national privately } \\
\text { owned bank }\end{array}$ \\
\hline $\mathrm{P}$ & $\mathrm{F}$ & $5-10$ & 1 & Director & Sustainability & $\begin{array}{l}\text { International pulp and paper com- } \\
\text { pany, publically listed }\end{array}$ \\
\hline Q & $\mathrm{F}$ & $10-15$ & 2 & Head of & Sustainability & $\begin{array}{l}\text { National pulp and paper company, } \\
\text { privately owned }\end{array}$ \\
\hline $\mathrm{R}$ & M & $10-15$ & 1 & Executive director & Sustainability & $\begin{array}{l}\text { National medium-sized bank, } \\
\text { privately owned }\end{array}$ \\
\hline $\mathrm{S}$ & $\mathrm{F}$ & $5-10$ & 1 & Manager & Sustainability & $\begin{array}{l}\text { National amusement park, privately } \\
\text { owned }\end{array}$ \\
\hline $\mathrm{T}$ & $\mathrm{F}$ & $3-5$ & 2 & Manager & Sustainability & $\begin{array}{l}\text { National medium-sized retailer, } \\
\text { privately owned }\end{array}$ \\
\hline $\mathrm{U}$ & $\mathrm{F}$ & $3-5$ & 2 & Head of & Sustainability and legal & $\begin{array}{l}\text { National outplacement company, } \\
\text { privately owned }\end{array}$ \\
\hline
\end{tabular}

questions (see appendix 1). In connection with each of the overarching questions, follow-up questions were asked, carefully making the respondent expand on and develop answers in areas of interest through simple "off-the-shelf" questions like "why", "in what way", "what happened", "what would be an example", and similar ones. During the interviews, it was of importance to make the managers describe and reflect on their professional role. Some issues were focused, such as the structural position, formal responsibilities, the closeness to top management, resource allocation, the required competences and backgrounds, practical work of the SM, integration of sustainability issues into overall strategy, as well as tasks related to integration and innovation. The respondents were also asked questions about conflicts and prioritizations 
related to the role. To enable a more analytical understanding of these issues, it was also of importance to find out what the interview person understood as problematic, interesting, helpful, disturbing, relevant, and irrelevant in their roleand how they coped with that.

The interviews were recorded and transcribed. The transcribed empirical material was read by one of the researchers and coded in terms of themes, inductively identified in the material as interpretative options or nodes (Alvesson \& Sköldberg, 2018). In detail, sentences or parts of sentences were sorted out if they contained references to different aspects of serving as a SMs (themes like task orientation, organizational structure, et cetera - see Table 2). Each theme was labeled with titles driven by the empirical text material. The transcribed interviews as well as the document with sorted themes were distributed to the three other researchers who read the material as well as discussed, changed and developed the sorted themes. This joint analysis also reduced the number of original themes from eight to six. In the end, one common issue for each theme lasted (for example 'Close to the top and handling a matrix' for the theme Organizational structure - see Table 2). This was also an example of a first-order analysis where themes were identified that were further analyzed.

For each theme, ambiguities in the role of the SM were identified and described (see Table 2). This was the secondorder analysis. These ambiguities contain uncertainties of meaning or content, and constitute in themselves tensions in the formation of the professional work of SMs. For example, the theme 'Task orientation: Assistant to business value or something else' that was ascribed the ambiguity "Sustainability or business performance". This step was also (just like the following ones) a joint one, discussed by all participating researchers who also read the interviews to check the relevance of the coding.

A third-order analysis was the identification of logics relating to the ambiguities (Kok et al., 2019; Nag et al., 2007; van Maanen, 1979). The logics, derived from the literature as market, bureaucratic and sustainability logics (Bondy et al., 2012; Freidson, 2001; Kok et al., 2019) reflect the underlying understandings of how SMs dealt with the ambiguities (see previous descriptions of the logics). In this step, the ambiguities were analyzed by means of the theoretical framework of the study to distinguish conceptually the logics behind the empirically described ambiguities (Kok et al., 2019; van Maanen, 1979; Nag et al., 2007; Gioa et al., 2013 - see Table 2). One example could be the identification of the logics 'sustainability logic' and 'market logic' based on the ambiguity 'Sustainability or business performance'. The point was not only to identify logics per se, but rather to identify how they were related to each other, that is, the complexity or dynamics of logics. This step, notably, also contained an analysis of the modes of interaction of different logics in the ambiguities. In the previous example, where sustainability or business performance was the ambiguity, a clash between sustainability and market logics was evident. As will be further detailed below, it was possible to identify clashes of logics, as well as a mix of logics, unclarity of logics and a balancing of logics as the underlying modes of how the logics related to each other (see, for example, Freidson, 2001). Each ambiguity was analyzed separately and not as, for example, a sequence, which means that they do not appear in a specific order of progress from each other.

In the following section, the ambiguities will be presented along with underlying complexities that are also further explained. The section precedes the empirical section of the paper where we go further into the ambiguities of task orientation, organizational structure, rank, necessity of the role, the nature of sustainability, and competence.

\section{Sustainability Managers, Ambiguities and Logics}

\section{Logics in Action and Emerging Model}

The empirical material below will be presented relating to specific themes of the SM work involving ambiguities. After identifying the ambiguities, these will be explained in terms of underlying complexity of logics, based on how the logics of sustainability, market, and bureaucracy relate to each other. In Table 2, an emerging model is pictured that will be further elaborated on in the empirical section and in the concluding discussion.

As will be shown, in all cases there is a distinct sustainability logic present in the role of the SM. The identified ambiguities show that there is a constant coexistence of more than one logic in the SM's work. The picture, as will be shown, is not one-sided or clear-cut, but complex. In some cases, the ambiguities reveal clashes between logics; sustainability logic on one side and market or bureaucratic logic on the other. In such a case, the logics are not compatible but stand in opposition to each other. That also means that they do not guide action in a clear way. In other cases, the sustainability logic is infused into the market logic; the complexity is characterized as a mix of logics, since both logics are operative but it is difficult to separate them given the situation. The ambiguities also show an even more complex situation when an unclarity of logics exists, implying reduced action-guiding capacity by the sustainability logic. Last, the ambiguities also illustrate situations of balancing between sustainability and market logics, when both logics are in use given the situation, requiring conscious decisions on what to do or enact. To be a SM, it will be argued, requires dealing with complexities of different logics inherent in the role. Below, we specify this in detail. The picture 


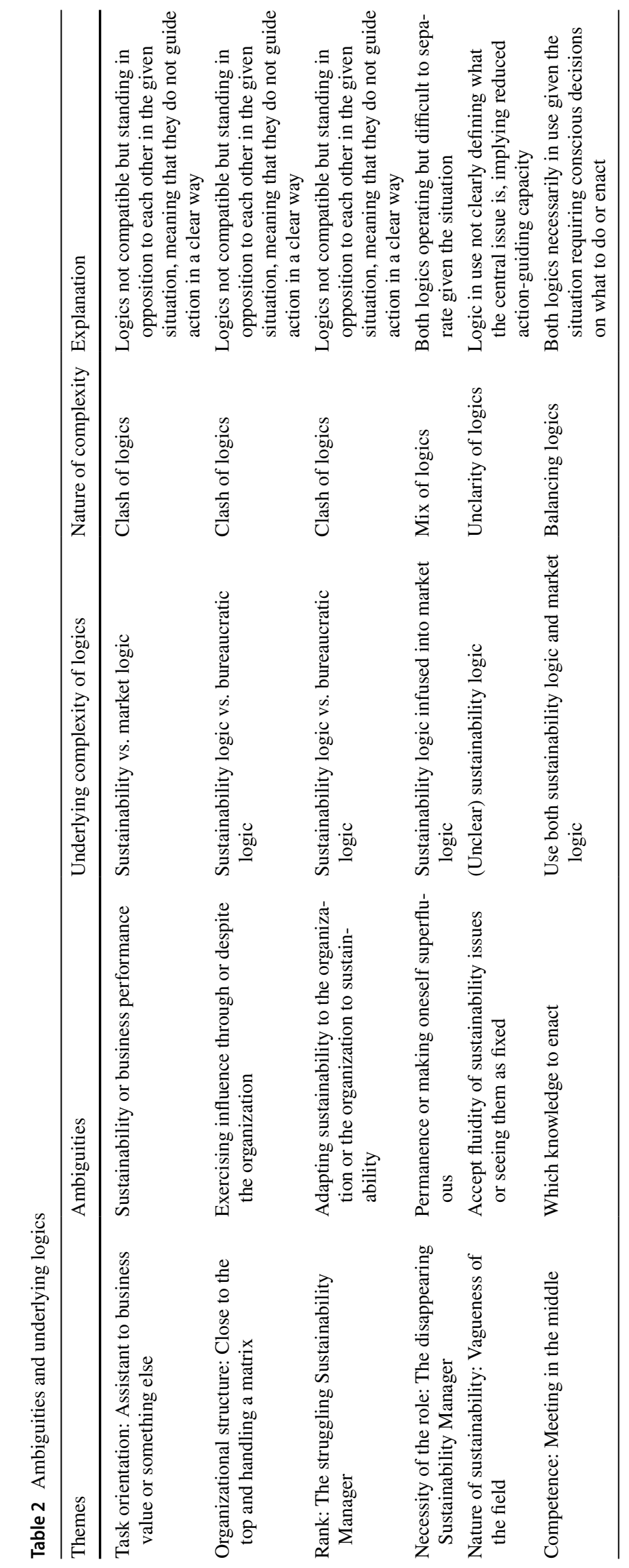


will be illustrated by citations from interviews with SMs and further discussed.

\section{Clash of Logics}

\section{Task Orientation: Assistant to Business Value or Something Else}

The interviewed SMs s bring up a number of themes relevant for their role, themes that in themselves contain ambiguities building on underlying clashes of logics. One example is the theme of Task orientation concerning what the SM is actually there to do. One could see task orientation as the underlying rationale of how to use the SM in the organization, to promote business, as an 'assistant to business value', a sustainability champion, an innovator, or something else.

Just a few respondents elaborate on the role they have for business development, many of the them do not. Some of the SMs mention that companies increasingly put sustainability into the center of business development and innovation, but that the SM is merely 'an assistant' in that process, rather than being at the center of it, contrary to the expectations.

SM M describes the role in business development as: “... to assist the organization, and bring in relevant knowledge and contribute.". SM P wants to work more with this but does not do it as much as wanted: In my case time is the limit. And of course you cannot be too many people at meetings with customers.". SM S says on her interaction with overall business strategy: "I do get invited, we had a conference with top management and I participated and gave my view.".

SM I says she is not always needed: "Many others in the organization also have good knowledge, if not, they come to me. But on the consumer side it is hard to get access, it is all about price.". But SM I also states that there are interactions: "Sustainability comes into sales, when giving an offer to a customer. That is the way it works also in the other direction, when we make a contract with our suppliers. So, it is both in our procurement and customer offerings that sustainability comes in.".

Some SMs s declare that they are increasingly given a role in promoting business and innovation, enhancing also business value. "You need to have an understanding of the value chain, with large suppliers and environmental branding of products, for example. The role of the SM in these cases is to be a coach for, for example, procurement, to be the voice of the customer and interpret demands for customers on sustainability." says SM J and continues: "It is about connecting suppliers with customers, to be transparent with suppliers, that these are the demands from customers.".

SM H underlines this: "I work a lot with innovation, where we look at future concepts and trends on sustainability. It covers studies with focus groups and new markets.
Sustainability is absolutely a future trend. We can make concept products, building on these trends.".

Such quotations show that the task orientation of the SM, what the manager is supposed to be, is not clear. Many and not always congruent ideas are triggered. The SM should be a business person, an innovator, a coach, an interpreter, the voice of the customers, a node for various stakeholdersand of course someone who works with sustainability. The complicated task orientation is also the consequence of a problematic situation where business and sustainability concerns seem to clash. There is ambiguity as to why the SM is there in the first place, to enhance sustainability or business performance (or both). Actually, the SM may have to make a choice between sustainability or business performance as the main issue. In practice, the underlying conflict refers to whether sustainability or market logic should prevail.

\section{Organizational Structure: Close to the Top and Handling a Matrix}

Conspicuously, however, the clash of logics does not only come about in terms of sustainability logic vs. market logic. It also has to do with sustainability in relation to bureaucratic ('organizational') logic. Of importance to the role are not only the material issues that the SM works with (see Task orientation), but also the structural conditioning of the role within organizational boundaries. Being close to top management (or part of it) generates a better position to deal with sustainability and to affect it. There is a preference of being 'selected' by top management and to have 'the ear of the CEO'.

The SMs s claim that the position should be close to the CEO and the TMT, but it is not always possible. At least the position should be as senior as the other functional executives, but preferably even closer to the CEO. As SM A says: "To be able to drive the issues you need to be close to top management. To be responsible for the function with a team and to report directly to the CEO.". SM T adds "It is preferable to have a position in the management team, but if not, at least have a very close cooperation. You will drive things that affect all other units and top management need to share the objectives and how to get there.".

Others voice hesitation on whether they should have a position in the TMT. It is a position that consumes a lot of time and energy on other topics than sustainability. Being close to power could be sufficient, according to SM B: "The most important thing is that the Sustainability Manager has a mandate to influence decisions. The position must be very close to the top management team.". One reason for not necessarily demanding a position in the TMT is that many other topics are discussed there. Engaging in the TMT is by some respondents understood as a waste of time and thereby downgrading other important tasks. Also, the need 
for a strategic take on sustainability can make the time spent in the TMT's meetings on operational issues wasted, according to SM C: "There is a lot of time spent on tactical topics in the top management team which can be a waste of the Sustainability Managers time." and continues: "Maybe one should change the agenda in the top management team so the Sustainability Manager can have a given place in these teams.".

SM K is one step down from the TMT but attends the meetings regularly when sustainability is on the agenda. "I might be in the top management team four times per year to discuss these issues. I get called in, you could say. The most important thing is that sustainability is discussed and decided on in the top management team. In my case, if I would be in the top management team, I would not have time for all the other things I need to do."

Another thing that the SMs bring up is that the sustainability organization itself is too small to be represented by a manager in the TMT, and hence it is represented by a manager that represents several functional areas.

In practice, many SMs end up in the situation of handling a matrix organization. The ideal situation, discussed by the SMs, seems to be that they should have a strong central role close to the CEO and at the same time exercise strong influence in the line organization via the use of a matrix organization. Ideally, strategies, policies, and goals are developed at top management level (including the SM), while the implementation of the details is carried out by line management with the SM and the sustainability organization as support.

As SM K expresses it: "The Sustainability Manager should drive the development of sustainability in the company, but it is not something you do on your own but together with other persons and departments. You have an overarching perspective on what sustainability issues we can make a difference in and what issues we have a responsibility for.".

The importance of working close to line managers that are responsible for decisions on their operations is perceived as crucial. The role of the SM is seen as very important for the implementation of sustainability and the interaction with line management needs to be close and even intense. The importance of sustainability in the functional organization is strongly emphasized by SM B: "Integration of sustainability without a sustainability organization does not work. Just as you cannot take away the HR function from the organization. The company will be like an amateur, ad hoc, without any edge. The work will fall apart and you will not be successful if you only involve line management.".

As for the matrix solution, some companies use a sustainability council to gather other functional managers, experts and line managers to discuss more informally priorities and processes. There are also multiple chains of command where a manager in the line organization can report to the line manager and the functional SM.
However, also hierarchy and the standing of the SM matter, as SM H argues: "We have a sustainability forum where we meet on certain issues. It can be, for example, cooperation on a new sustainability strategy; that type of issues. Then, you manage it through the participating managers. I sit in a higher position hierarchy-wise; their managers' report on a lower level than I do. I can follow-up with their managers. You need to have a mandate, a hierarchical position, otherwise it will be impossible to handle.".

The question of organizational structure refers to where in the organization the SM is placed. Matrix organizations may involve a higher capacity to influence both from an advisory function and within the line organization, implying a stronger mandate. Whatever the case, the SM is always subject to structural prioritizations, implying which position the manager gets and the possible influence that can be exerted.

Seen as an ambiguity, a structural struggle of the SM is to promote the agenda of sustainability, in practice exercising influence through or despite the organization. Being close to the top becomes a means through which sustainability can be promoted - but also a risk of being caught by insignificant issues. This is about influence to promote sustainability. Since this can only be done within the organizational frames and the hierarchy (albeit sometimes in network structures), sustainability ambitions (and logic) stand against a structural context underpinned by the bureaucratic logic of a hierarchy. In other words, there is a clash between the sustainability logic and a bureaucratic logic when it comes to the structural position of the SM.

\section{Rank: The Struggling Sustainability Manager}

Another issue relates to 'the struggling Sustainability Manager' and that of getting the others 'onboard'. This is a constant and frequently ongoing situation where the SM is fighting for influence and for improved standing of sustainability in the organization. It concerns rank, not in a formal structural sense (cf. Organizational structure above), but more in the sense of the ranking or positioning of sustainability as a material topic in the organization. To promote sustainability becomes an important and delicate task of the SM. It requires a lot of work and skills in change management. A number of techniques and tactics are used in reference to other managers to increase the standing of sustainability in the organization.

SM F explains the informal organization that the SM needs to understand and manage, in addition to the formal line organization and the formal matrix organization. "You have unofficial leaders that can take the sustainability issues forward, but they can also make resistance. It is like an invisible network that you need to understand, and why issues are progressing or not, so you can navigate and get a result." 
SM B relates this to ethics and how the SM is responsible for issues of what is right and wrong for a company. This is something SM B tries to implement in the organization and among line managers: "It is challenging, it gets close to ethical questions and can be in conflict with other objectives in the company. It gives the sustainability manager a special role, a unique role because it contains moral issues that HR and other functions do not have.".

SM M relates the resistance to the nature of change connected to the SM role and emphasizes the need to connect sustainability to market logic. "It is a big part of your day to day work, to bring in a new perspective and meet resistance, which you need tackle in a constructive way to avoid a fight." SM M continues: "Sustainability is complex and abstract. It is hard to handle for organizations, for companies that are actions and solutions oriented. It is hard to follow an ordinary business logic and introduce sustainability there, but you have to do that too.".

The respondents point to frustration among SMs in general, referring to 'the others in the company' that do not understand sustainability issues, and the low level of knowledge on sustainability in the organization. They also point to a number of SMs that have resigned from their positions as a public protest against the lack of support from the others in the company. As SM C puts it: "I have a lot of lunch meetings with other SMs and there is an enormous frustration. The others in the company do not understand and do not have knowledge about the sustainability issues. /.../This is a struggle, when someone taps you on your head all the time. You need to shoulder a bigger role in the company but many do not know what the role should be. It is easy to step into other areas and then you do not get popular. You need to define your role.". SM $\mathrm{S}$ also expresses frustration with "the others in the company": "You have to be there and remind them constantly. In my darkest hours I think: Is it always up to me? If I do not stress this, will it not be done?". Education inside the organization is, in addition to the business case mentioned above, also mentioned as an important. The role of the $\mathrm{SM}$ is to create a joint internal understanding of sustainability and to get alignment in the organization.

SM O says that the issue is not resistance to sustainability as such. In a smaller organization it is more about getting time and resources among all other things: "Everyone, in principle, agrees it is the right thing, only that we need to do all these other things first. It is not because no one wants to, but because there are so many other things to do.". No ideological conflicts exist around sustainability; everyone believes that it drives financial value in the end. "It is nice to feel it is not an issue whether this is profitable or not, everything we have done is because it has been profitable or for saving costs, there has been no contradiction at all here.", says SM O.
SM Q also finds little resistance to sustainability as such-but rather to change: "The hardest is to get the others with you. There are many who think that sustainability is one thing and business operations is something else. They think both are good, but they have a problem seeing the sustainability perspective. Or they want to own the issues themselves. Everyone wants to work with sustainability and name what they do sustainably."

These quotations express the organizational realities that the SMs face. Prioritizations, and to some extent resistance, resources, power structures and interests, matter. That is, sustainability issues are promoted by the SMs, but conditioned by the organizational frame. The challenge or ambiguity for the SMs seems to be the issue of adapting sustainability to the organization or the organization to sustainability. Essentially, this is a conflict between sustainability logic and bureaucratic logic in the sense that there is a promotion of sustainability as a topic confined by organizational structures. The SMs explain that they must deal with resistance in the organization and defend their position and the role of sustainability. But that does not mean that people resist the need to be sustainable as a company overall. Rather, it concerns the role the SM should play, how sustainability is to be implemented, and how strategic and visionary the company should be. Their ambitions sometimes seem to be much higher than the rest of the organization. The task is to create a role for sustainability in the organization, but this entails finding a place for sustainability within the command structure of the organization.

\section{Mix of Logics}

\section{The Necessity of the Role: The Disappearing Sustainability Manager}

Another issue is the necessity of the $S M$, and the idea that the role disappears as sustainability is further integrated into organizational processes (cf. Risi \& Wickert, 2017). The interviewed SMs strongly disagree with the notion that it is a temporary position that will not be needed once the company has become truly sustainable and sustainability has been integrated in its operations. As expressed by SM D: "The talk about taking away the Sustainability Manager is the most stupid one I ever heard. It does not work. It is the same thing as saying: this is not important. You need a Sustainability Manager and a sustainability organization and then you need to work in a large network in the company.".

SM B expresses a similar opinion: "It is naïve to believe that a change of business life to increased sustainability goes that fast. There is no other function in the company that is discussed in the same way. This is a fundamental issue in business that will not go away.". SM E adds: "I work to get rid of myself" - you hear that 
sometimes from sustainability managers. It is never going to happen. A sustainability function is needed to support the business leaders. /.../ Everything is supposed to be integrated, it is impossible as a manager to be an expert on everything. It is the same thing as with HR where you once upon a time said that all managers should know $H R$.”.

SM E once had the notion that the role was temporary: "I used to think so before, but I have changed my mind. There has to be someone who guarantees a proper management of these issues and that you are on the right track. /.../To me this is a new profession, in the future you might see other functions reporting to sustainability, like communication and HR, since sustainability has the big picture and how it sticks together.".

Almost all respondents touch upon this topic and express irritation of the debate itself. It is claimed that it is a new profession, and that the function is needed. There are many arguments from the interviews in favor of a permanent position. Several SMs emphasize that sustainability is a strategy, not a singular issue to be handled, and hence it needs constant governance by professionals. Sustainability is perceived as fundamental and needs evidence-based handling by experts. Also, having a SM demonstrates that the company recognizes sustainability as important.

Only two of the SMs, M and P, see 'the disappearing SM' as something positive. SM M has experienced a change with a less influential and more integrated role than before, a form of partial 'castration' of the role: "Now I can study what happens when you castrate it a little bit, as we have done. Sustainability needs a strategic weight and maybe you get that with a head of sustainability role, but in the future, I think it is overplayed, maybe in 5-10 years.". SM P comments in a similar way: "Do we need sustainability managers, what has happened within ten years? Maybe we do not need anyone called Head of Sustainability. Maybe it is then integrated into the operations, but I do not know. It will be interesting to see.".

What we can infer from this is that the structural role of the SM might be under threat, but also that it is, from their perspective, necessary in order to emphasize, manifest, and implement sustainability in the organization. The ambiguity, however, relates to the role. Is it permanent or is it reasonable to make oneself superfluous? One could argue that the matter is about how to mix sustainability logic and market logic, rather than integrating (or not) sustainability into the business. If integrated in all business processes 'automatically', the (widened) market logic would suffice. If so, sustainability as an issue of its own has had its time.

\section{Unclarity of Logics}

\section{The Nature of Sustainability: Vagueness of the Field}

Several SMs point to the vagueness of the (sustainability) field and its character of change, where new topics enter the field over time. There are many topics that can be included in the area of sustainability and these topics change over time as stakeholders' perspectives change. Accordingly, the demands from stakeholders come in new shapes as new issues enter the public debate. As SM K expresses it: "It is a large and broad role, the issues are immensely wide. They cover anything from environment to packaging, employee issues, diversity and social responsibility in the market. It is so wide and includes so many people and so many contacts with stakeholders. /.../ What is demanding in this role is that there is no end to all the things you could do, it can get so big. You can always drive the issues more; you can always communicate more. You have to make priorities.". This is basically an 'ontological' question of sustainability. It is fluid, and changes character over time. The nature of sustainability requires ongoing (re-)definition.

SM I expresses almost the same view, that more and more topics are added. GDPR (The General Data Protection Regulation of the EU) is mentioned as an example: "The role of the Sustainability Manager is always very wide. When we talk about sustainability, we do it in very broad terms. I think it is important for every organization and every manager to know what they are trying to embrace. Over the years it has been about the same challenges that you include, rarely less, rather more and more" and continues: "The areas of expertise change, now it is, for example, GDPR.".

From a professional point of view, this is not only a matter of defining sustainability. It also prompts SMs to be flexible, open to change and to expand competence. SM N argues: "You need to be open to learn new areas all the time and be aware that you do not know everything. It is such a complex field that changes all the time. It is not possible to know all the details about everything." and continues: "You must keep an open mind and be humble for your work tasks; you need to take help from others and try to be updated.".

The vagueness and change of the field, thus, requires personal adaptability and a flexible self with a readiness to learn and adapt. This also influences how the role is organized to make flexibility possible, says SM J: "The role is so broad and spans over so many things. That makes analyzing the [sustainability] trend important but also the networking role. This role also changes over time, depending on what issues are considered as important. You have to be flexible in how you organize things.".

This vagueness of the field forces SMs as well as other people to adapt their roles over and over again, also within the organization. SM I explains it in the following way: 
"People change roles all the time in the matrix organization and it makes it hard to manage it. Once you have anchored well and built good relations, the persons are exchanged. I think it is better to work with the same people over time. /.../ It can take two years before it is natural for people in the organization to work as I want them to, but some of them suddenly leave and you have to start all over again.". Thus, the vagueness of the field makes it difficult to establish organizational positions, scopes, and duties of the SM. He or she is essentially subject to exogenous demands, forming both the position, demands for competence, and work tasks.

This vagueness of the field, as well as a fluid network of involved people, makes the role complex to handle. New sustainability topics come and go, stakeholder demands change, as does the sustainability discourse in the society. The nature of sustainability is a concern the respondents express like a never-ending process where almost any topic could be included, from climate change to GDPR. This also makes implementation of activities and routines harder as people in the networks change over time. New types of experts are needed and other parts of the organization are subject to new sustainability demands.

The nature of sustainability can be problematized as an ambiguity; either you fix sustainability issues or you see them as fluid. If fixed, you risk capturing only part of all relevant issues. For the SM (and others), the problem remains to decide on which organizational issues that the sustainability logic should be applied to. That is, the underlying complexity relating to logics is not a clash between the sustainability logic and other logics, but lacking clarity within the logic since it does not (in this case) function as an actionguiding principle as to which issues that should be related to sustainability. Sustainability, thus, becomes problematic to handle.

\section{Balancing Logics}

\section{Competence: Meeting in the Middle}

Defining and conditioning the SM's possibilities to work is also his or her background in terms of education, knowledge and experiences. The interviews confirm varying educational and professional backgrounds. Nor is there any consensus on which skills, training and basic knowledge you should have as a SM, or even what a career looks like.

Some stress that a SM should have a background in the field of natural sciences, while others mention social sciences. SM C stresses the former: "I think you need some type of background from natural sciences, unless you have it somewhere else in the organization. You must understand the planetary problems. I have been in heavy industries and I need to understand thermodynamics, because I get questions about that. I want to be credible in my industry and it is helpful with a civil engineering degree. To be able to answer the questions, it is good (to have), and I do this with the help of natural sciences.".

Some think an expert background is good - being an expert on sustainability issues - while others emphasize a managerial background and leadership skills. As expressed by SM D: "Primarily you need knowledge about sustainability. I have worked a lot with environmental managers and they have a good knowledge of everything within the field of environment, climate, recycling, and so on. But you also need to be good at leadership, lobbying as well as understanding structures and demands in an organization.".

SM D elaborates on the importance of leadership skills as well as fundamental environmental competence, adding that it also depends on which industry you are working in, for example in the financial sector. This is underlined also by SM E, who works at a bank: "I think a master in business and sustainability is the best educational background. If you are for example a biochemist or an environmental expert, it is very hard to be in a bank. You must understand the sustainability issues, but you must also know the business perspective.".

Other SMs claim that the type of industry matters. You find more social responsibility issues in the service industry and more environmental issues in the manufacturing industry. A relevant combination of knowledge can also vary depending on which other roles and competencies that exist in the organization. One example could be an organization with many environmental experts, which would open up for a SM with a business background.

However, many of the interviewed managers argue that the demands are changing and increasing rapidly. The future SM must have all the above skills or experiences, or at least many of them to be successful on the job. The SM needs to have an understanding of both technical, societal and management issues connected to sustainability. Thus, the SM needs to 'meet in the middle' on the scale of expert vs. generalist knowledge as well as technical vs. societal background.

SM A expresses this duality: "A Sustainability Manager can come from both camps, sustainability or business, but you have to jump over to the other side regardless. You have to learn to stand with the feet in both worlds and earn respect on both sides. The sustainability expert needs to understand the business, while the business side needs to show that they understand sustainability.".

In the interviews, the managers line up a number of issues and topics that a SM should master. This includes change management, business strategy, leadership and communication, in addition to knowledge about social and environmental responsibility. The role becomes much more complex and advanced than before. SM F makes a joke about it: 
"The time is over with these male engineers that were both birdwatchers and heads of environment in companies at the same time.".

In line with the issue of 'meeting in the middle' the managers recognize a need to develop their sustainability expert role and their role as senior managers. SMs with a general management background need to develop their expert knowledge, while SMs with an expert background need to develop their management skills. The ambiguity lies on an individual level, how to handle contradictions as to the ideally expected mix of competences; natural sciences, social sciences, specific sustainability knowledge, business and operations knowledge, leadership and management skills, industry competence, and so on. Which knowledge to enact reflects an underlying ambiguity. In practice, you have to balance knowledge from different fields, both business and sustainability.

\section{Concluding Discussion}

Linking back to the purpose of this study-to identify the professional logic of SMs - and its specific research question about what is contained within a professional logic of SMs, some aspects can be noted. To answer the research question, we have identified and set off from six ambiguities in which SMs enact logics within their professional role.

What we find is not a single and distinct phenomenon, a professional SM logic clearly separable from other logics: The SM logic is not 'monolithic' —of one particular content or kind-but 'polylithic' and related to sustainability, business, and bureaucracy, all of which condition the SM's work. The professional logic of SMs is not a specific phenomenon in 'splendid isolation'. Rather, it can be seen as a meta-construct of three different logics — of sustainability, market, and bureaucracy - that relate to each other in complex ways. That is, we do not just identify the components of a professional SM logic, but also reveal how underlying logics relate to each other.

What we mean by that is that within the situation or context where the professional logic is enacted by the SM, there is no simple action-guiding principle or understanding of what to do and how to deal with issues. Rather, there is a complexity consisting of clashes between (underlying) logics as well as mixed and balanced logics, given the ambiguous situations. In addition, not even the sustainability logic is always clear-cut and action-guiding, due to the unclarity identified in relation to one ambiguity. A professional logic reveals how you interpret reality and act upon it. If it is vague and builds on partly contradictory logics, your actions will be conditioned by these-and what you do as a SM will be a result of considerations stemming from clashing, mixed, unclear, and balanced logics. That will affect you as a SM at work. Paying attention to this complexity should make us avoid some pitfalls, for example reducing the issue of the professional logic of the SMs by describing sustainability logic as the professional SM logic. If it were, the "committed activist CSO' (Wright et al., 2012) would epitomize the $\mathrm{SM}$, which is clearly not the case, to judge from our study. Neither do we find SMs acting upon or expressing pure market concerns or pointing to bureaucratic structures as fundamental reasons for acting. In other words, there is no obvious 'simple' principle or understanding of how to look upon, interpret or organize work from a professional point of view. The professional logic has no simple interpretative and action-guiding capacity (cf. Friedland \& Alford, 1991).

What one could say is that the professional role of SMs involves ongoing and problematic challenges dealt with by means of the logics. We would argue that it is not just about balancing of bridging different interest in the organization (Wright et al., 2012), a practical aspect. It is true that SMs must tend to paradoxes when it comes to sustainability priorities (Hahn et al., 2014, 2018). They must deal with “... interrelated yet conflicting economic, environmental, and social concerns with the objective of achieving superior business contributions to sustainable development." (Hahn et al., 2018, p. 237). One important aspect of this, also relevant to the SM role (cf. the ambiguity about the nature of sustainability), is that one has to accept tensions and try to reach different sustainability objectives simultaneously, even if they are in conflict. But as we believe, through focusing on logics, we go beyond the discussion on conflicting interests within organizations. Rather, we point to the dynamics that make a coherent and consistent professional logic of SMs complex (cf. Brès et al., 2019; Kok et al., 2019). Even though the professional identity of SMs has been studied (Carollo \& Guerci, 2018; Wright et al., 2012), as well as the relationship between institutionalization and (SM) professionalization (Bondy et al., 2012; Risi \& Wickert, 2017), the focus on logics captures both the ways SMs enact their role and the possibilities of a SM profession in general, 'requiring' a distinct professional logic.

Two overarching reflections can be made. First, SMs are not professionals in the traditional sense of the word. Notwithstanding some outer signs of increased professionalism (education, networks, etc.), the SM remains an 'organizational professional' (Brès et al., 2019; Evetts, 2009). That is, the professionalism of the SMs is probably best described in terms of the 'new' organizational professionalism - in comparison to 'old' occupational professionalism - that has been discussed in recent years (Evetts, 2009; see also Brès et al., 2019). SMs seem to be 'professional' in the sense of meeting organizational expectations and mandates, while simultaneously promoting sustainability within their organizations. In contrast to traditional professions defined through collegiality, the 
profession conditioned by the organization is to a high degree limited by its control structures. Somewhat paradoxically, and relating to the expansion of CSR professionals, the marketization of sustainability and the more prominent role of SMs in business have made the development of a 'new' profession more problematic compared to, for example, if it had been characterized only by standalone CSR consultants, driven by a sustainability logic or even ideology (see e.g., Windell, 2006). Without the frames of the business organization (and to some extent the market), idea- or mission-driven professionals have another way of formalizing and structuring themselves in a professional context.

Second, and relatedly, what the SM will do and how the profession will develop given the current situation, will be conditioned by the structural context where the SM role has emerged. That context differs completely from the ones in which traditional professions once developed, for example lawyers, medical doctors and accountants (see, for example, Ackroyd, 1996). Due to the organizational and market structure that frames and even creates the role of the SM, it is reasonable to situate their professional logic within sustainability and that structure. The manifestation of this professional logic takes place within the organization. The sustainability ethos of some SMs can indeed be seen as reflecting what is institutionalized at the societal level (normative expectations relating to sustainability, see Herremans et al., 2009; Bondy et al., 2012). But in the case of SMs it is only realized within the organizational context. It is, so to speak, situated. SMs exercise influence through or despite the organization.

Based on this, one can reflect on the mandate that the SM is given. If sustainability is aspired for in and by the organization, it is of utmost importance to understand and to give leeway for the mandate of the SM. There is an obvious link to role and organizational design in this. What the organization wants to achieve in terms of sustainability is actually reflected in the mandate of the SM. Due to the complex situation of the SM, top managers have a responsibility ensure such a mandate if they are seriously interested in this. As we see it, it is also a matter of ethical and identity-related reflection necessary in the organization.

Being specific about the contributions of the article, the study contributes empirically through identifying and analyzing specific themes and ambiguities that expose how underlying logics relate to each other and make the SM professional logic vague and complex. This is, we argue, also of practical relevance. To put it simply, it is difficult to work as a SM because there is no simple professional logic, but rather a complexity of underlying action-guiding logics necessary to enact in various ways to master the role. When the position of the SM gets stronger and more institutionalized, this is also of high relevance in the education of future SMs and specialists, since an understanding of what it takes to be a SM is necessary, including the difficulties. Preparing future SMs for a complex work situation requires knowledge of the predicament of these professional actors, and hopefully this article contributes at least moderately to that.

As for the theoretical contribution of the article, we believe that it relates to the literature on professions and professional logics in the sense that it explains the difficulties of certain occupations to establish themselves qua professions. The 'monolithic' logic of traditional professions is not found among SMs. The professional logic of SMs is a complex meta-construct, containing underlying clashes of different logics, as well as a mix, unclear contents and a delicate balancing between logics. The 'rules of the game', the norms, the underlying understandings of professional activities are not clear enough to inform and to 'separate' SMs as professionals. That is also relevant to the literature on professionalization. We point to an important reason why certain occupations have difficulties to establish themselves as professions. The logic that they build on simply does not refer to a professional activity (such as law or medicine) that distinguishes itself so much that it is capable of 'having' its own professional logic of action-guiding kind. It is a professional activity established within the context of the organization.

In pointing to the 'newness' of the SMs, we capture a vague professional logic that is more or less under construction. That is, we do not depart from an idea of a relatively strong existing professional logic or attempts to professionalize a certain professional group (among many, e.g., Lee, 1995). For that reason, the complexity that SMs face is not a matter of, for example, a market logic entering the scene and clashing with a traditional professional logic (cf. Seger, 2018). Rather, the study suggests that a 'monolithic' professional logic does not exist for SMs, but rather a problematic and partly confusing construct involving a variety of logical clashes, mixes, unclarities, and balances. Not only the logics of sustainability and the market are present (cf. Dahlmann \& Grosvold, 2017; Frostenson \& Helin, 2017; Kok et al., 2019), but also the logic of bureaucracy (Freidson, 2001). In line with Hayes and Rajão (2011), who identify a number of co-existing logics, we do not see a conflict or configuration of only two logics. Rather, the sustainability logic is always, in various ways and configurations, co-existing with these other logics within the organizational context in which the profession has emerged. Similar to what Goodrick and Reay (2011) claim about pharmacists, we suggest that the professional work of SMs is guided by a constellation of logics derived on the one hand from broader society, and on the other hand of the organizational realities of the business context of SMs.

As for the limitations of the article, it may be the case that it has a contextual bias. It is based on interviews with 21 Swedish-based SMs in a variety of industries. Some of the companies are subsidiaries of international corporations 
and many have operations also outside Sweden. Despite that, there might be aspects of serving as a SM in Sweden in relation to other countries, for example certain understandings of sustainability in the work context, relating to the Swedish tradition of cooperation between top management and trade unions as well as rather low hierarchical barriers. Such factors might impact the results of the study, for example through a less emphasized managerial approach to the tasks at hand. We welcome broader studies of SM professional logic that include SMs from other countries and cultures.

Also, we focus on individual SMs and how they reason. Others may prefer to contextualize the SM role within sustainability teams or management settings, capturing a more comprehensive and possibly collective form of work (dynamics). Furthermore, our study does not focus on the development of the profession over time or on issues such as education, academic incorporation, network organizations, professional codes, or certifications-all of which are other contextual aspects. Its point of departure is from 'within' the organization. But, once again from a contextual perspective, more studies should also focus on how the role of the SM develops, not least in relation to business strategy (Miller \& Serafeim, 2014; Vallentin \& Spence, 2017). Similarities and differences compared to other professions, such as the HR professional, deserve attention.

\section{Appendix 1}

\section{Interview Guide}

What is your personal professional background?

How do you organize sustainability in your company?

What is your view of the role of the SM?

What are the major challenges for a SM?

Which competence should a SM have?

Which professional background should a SM have?

How do you organize and manage sustainability from the perspective of a SM?

How do you handle relations to other managers?

Which position should a SM have?

Which role should the SM take in connection to overall business strategy?

What else would you like to add?

Acknowledgements We gratefully acknowledge financial support for this research by Handelsbankens Forskningsstiftelser, Grant number P2017-0086:1.

Funding Open access funding provided by Örebro University. This study were funded by Handelsbankens Forskningsstiftelser (Grant No. P2017-0086:1).

\section{Declarations}

Conflict of interest No conflicts of interest are reported for this article.

Open Access This article is licensed under a Creative Commons Attribution 4.0 International License, which permits use, sharing, adaptation, distribution and reproduction in any medium or format, as long as you give appropriate credit to the original author(s) and the source, provide a link to the Creative Commons licence, and indicate if changes were made. The images or other third party material in this article are included in the article's Creative Commons licence, unless indicated otherwise in a credit line to the material. If material is not included in the article's Creative Commons licence and your intended use is not permitted by statutory regulation or exceeds the permitted use, you will need to obtain permission directly from the copyright holder. To view a copy of this licence, visit http://creativecommons.org/licenses/by/4.0/.

\section{References}

Abbott, A. (1988). The system of professions. The University of Chicago Press.

Ackroyd, S. (1996). Organization contra organizations: Professions and organizational change in the United Kingdom. Organization Studies, 17(4), 599-621.

Acre (2011). The emergence of the chief sustainability officer. Acre Resources. Retrieved December 21st, 2021, from http://assets. acre.com/white_papers/The_Emergence_of_the_CSO.pdf.

Albert, S., \& Whetten, D. (1985). Organizational Identity. In L. L. Cummings \& B. M. Staw (Eds.), Research in organizational behaviour 7 (pp. 263-295). AI Press.

Alvesson, M., \& Sköldberg, K. (2018). Reflexive methodology: New vistas for qualitative research (3rd ed.). London.

Bailey, M. (2011). Policy, professionalism, professionality and the development of HR practitioners in the UK. Journal of European Industrial Training, 35(5), 487-501.

Bailey, M. (2015). Professional development of HR practitioners - A phenomenographic study. European Journal of Training and Development, 39(3), 220-238.

Bévort, F., \& Suddaby, R. (2016). Scripting professional identities: How individuals make sense of contradictory institutional logics. Journal of Professions and Organization, 3(1), 17-38.

Bondy, K., Moon, J., \& Matten, D. (2012). An institution of corporate social responsibility (CSR) in multi-national corporations (MNCs): Form and implications. Journal of Business Ethics, 111(2), 281-299.

Borglund, T., De Geer, H., \& Sweet, S. (Eds.). (2017C). CSR and sustainable business. Sanoma Utbildning.

Brès, L., Mosonyi, S., Gond, J., Muzio, D., Mitra, R., Werr, A., \& Wickert, C. (2019). Rethinking professionalization: A generative dialogue on CSR practitioners. Journal of Professions and Organization, 6, 246-264.

Carollo, L., \& Guerci, M. (2018). 'Activists in a suit': Paradoxes and metaphors in sustainability managers' identity work. Journal of Business Ethics, 148(2), 249-268.

Dahlmann, F., \& Grosvold, J. (2017). Environmental managers and institutional work: Reconciling tensions of competing institutional logics. Business Ethics Quarterly, 27(2), 263-291.

De Geer, H., Borglund, T., \& Frostenson, M. (2009). Reconciling CSR with the role of the corporation in welfare states - the problematic swedish example. Journal of Business Ethics, 89(3), 269-283. 
DiMaggio, P. J., \& Powell, W. W. (1983). The iron cage revisited: Institutional isomorphism and collective rationality in organizational fields. American Sociological Review, 48(2), 147-160.

Dunn, M. B., \& Jones, C. (2010). Institutional logics and institutional pluralism: The contestation of care and science logics in medical education, 1967-2005. Administrative Science Quarterly, 55(1), 114-149.

Eccles, R. G., \& Krzus, M. P. (2015). The integrated reporting movement - Meaning, momentum, motives and materiality. Wiley.

Elg, M., Gremyr, I., Hellström, L., \& Witella, L. (2011). The role of quality managers in contemporary organiszations. Total Quality Management, 22(8), 795-806.

Evetts, J. (1999). Professions: Changes and continuities. International Review of Sociology, March 1.

Evetts, J. (2003). the sociological analysis of professionalism: Occupational change in the modern world. International Sociology, $18(2), 395-415$

Evetts, J. (2009). New professionalism and new public management: Changes, continuities and consequences. Comparative Sociology, 8(2), 247-266

Fournier, V. (1999). The appeal to 'professionalism' as a disciplinary mechanism. Sociologic Review, 47(2), 280-370.

Freidson, E. (1999). Theory of professionalism: Method and substance. International Review of Sociology, 9(1), 117-129.

Freidson, E. (2001). Professionalism: The third logic. University of Chicago Press.

Friedland, R., \& Alford, R. (1991). Bringing society back in: Symbols, practices, and institutional contradictions. In W. Powell \& P. DiMaggio (Eds.), The new institutionalism in organizational analysis (pp. 232-263). University of Chicago Press.

Frostenson, M., \& Helin, S. (2017). Ideas in conflict: A case study on tensions in the process of preparing sustainability reports. Sustainability Accounting, Management and Policy Journal, 8(2), 166-190.

Fu, R., Tang, Y., \& Chen, G. (2020). Chief sustainability officers and corporate social (Ir)responsibility. Strategic Management Journal, 41(4), 656-680.

Gioia, D. A., Corley, K. G., \& Hamilton, A. L. (2013). Seeking qualitative rigor in inductive research: Notes on the Gioia methodology. Organizational Research Methods, 16, 15-31.

Gond, J., Igalens, J., Swaen, V., \& El Akremi, A. (2011). The human resources contribution to responsible leadership: An exploration of the CSR-HR interface. Journal of Business Ethics, 98, $115-132$.

Goodrick, E., \& Reay, T. (2011). Constellations of institutional logics: Changes in the professional work of pharmacists. Work and Occupations, 38(3), 372-416.

GreenBiz (2018). State of the profession, 2018. Davies, J. GreenBiz. Retrieved December 21st, 2021, from https://www.greenbiz.com/ article/state-sustainability-profession-2018.

Greenwood, R., \& Lachman, R. (1996). Change as an underlying theme in professional service organizations: An introduction. Organization Studies, 17(4), 563-572.

Guerci, M., \& Pedrini, M. (2014). The consensus between Italian HR and sustainability managers on HR management for sustainabilitydriven change - towards a 'strong' HR management system. The International Journal of Human Resource Management, 25(13), $1787-1814$.

Hahn, T., Figge, F., Pinkse, J., \& Preuss, L. (2018). A paradox perspective on corporate sustainability: Descriptive, instrumental and normative aspects. Journal of Business Ethics, 148, 235-248.

Hahn, T., Preuss, L., Pinkse, J., \& Figge, F. (2014). Cognitive frames in corporate sustainability: Managerial sensemaking with paradoxi$\mathrm{cal}$ and business case frames. Academy of Management Review, 39(4), 463-487.
Hambrick, D. C., \& Mason, P. A. (1984). Upper echelons: The organization as a reflection of its top managers. Academy of Management Review, 9(2), 193-206.

Hayes, N., \& Rajão, R. (2011). Competing institutional logics and sustainable development: The case of geographic information systems in Brazil's Amazon region. Information Technology for Development, 17(1), 4-23.

Herremans, I. M., Herschovis, M. S., \& Bertels, S. (2009). Leaders and laggards: The influence of competing logics on corporate environmental action. Journal of Business Ethics, 89, 449-472.

Johnstone, L. (2019). Theorising and conceptualising the sustainability control system for effective sustainability management. Journal of Management Control, 30, 25-64.

Jutterström, M., \& Norberg, P. (Eds.). (2013). Corporate responsibility - CSR as a management idea. Edward Elgar.

Kanashiro, P., \& Rivera, J. (2019). Do chief sustainability officers make companies greener? The moderating role of regulatory pressures. Journal of Business Ethics, 155(3), 687-701.

Kok, A. M., de Bakker, F. G. A., \& Groenewegen, P. (2019). Sustainability struggles: Conflicting cultures and incompatible logics. Business and Society, 58(8), 1496-1532.

Larson, M. (1978). The rise of professionalism. Berkeley University Press.

Lee, T. (1995). The professionalization of accountancy: A history of protecting the public interest in a self-interested way. Accounting, Auditing and Accountability Journal, 8(4), 48-69.

Martin, J., Elg, M., Gremyr, I., \& Wallo, A. (2019). Towards a quality management competence framework: Exploring needed competencies in quality management. Total Quality Management and Business Excellence, 32, 359-378.

Miller, K., \& Serafeim, G. (2014). Chief sustainability officers: Who are they and what do they do? In R. Henderson, R. Gulati, \& M. Tushman (Eds.), Leading sustainable change (pp. 196-224). Oxford University Press.

Mintzberg, H. (1979). The structuring of organizations: A synthesis of the research. Prentice-Hall.

Muzio, M., Brock, D. M., \& Suddaby, R. (2013). Professions and institutional change: Towards an institutionalist sociology of the professions. Journal of Management Studies, 50(5), 699-721.

Nag, R., Corley, K. G., \& Gioia, D. A. (2007). The intersection of organizational identity, knowledge, and practice: Attempting strategic change via knowledge grafting. Academy of Management Journal, 50(4), 821-847.

O'Neill, R. (2016). Closing the sustainability-investor relations gap: Engaging stakeholders research. SustainAbility.

Pache, A.-C., \& Santos, F. (2010). When worlds collide: The internal dynamics of organizational responses to conflicting institutional demands. Academy of Management Review, 35(3), 455-476.

Painter-Morland, M., Sabet, E., Molthan- Hill, P., Goworek, H., \& De Leeuw, S. (2015). Beyond the curriculum: Integrating sustainability into business schools. Journal of Business Ethics, 139(4), 737-754.

Parsons, T. (1964). Essays in sociological theory. The Free Press.

Peters, G. F., \& Romi, A. (2014). Does the voluntary adoption of corporate governance mechanisms improve environmental risk disclosures? Evidence from greenhouse gas emission accounting. Journal of Business Ethics, 125(4), 637-666.

Peters, G. F., Romi, A., \& Sanchez, J. M. (2019). The influence of corporate sustainability officers on performance. Journal of Business Ethics, 159(4), 1065-1087.

Porter, M., \& Kramer, M. (2006). Strategy and society: The link between competitive advantage and corporate social responsibility. Harvard Business Review, 84(12), 76-89.

Porter, M. E., \& Kramer, M. R. (2011). Creating shared value. Harvard Business Review, 89(1/2), 62-77. 
Risi, D., \& Wickert, C. (2017). Reconsidering the symmetry between institutionalization and professionalization: The case of corporate social responsibility managers. Journal of Management Studies, 54(5), 613-646.

Rucci, A. (1997). Should HR survive? A profession at the crossroads. Human Resource Management, 36(1), 169-173.

Scott, W. R. (2008). Lords of the dance: Professionals as institutional agents. Organization Studies, 29(2), 219-238.

Seger, K. (2018). Institutional logics and accounting professionals: The case of $K 2$ and K3. Doctoral dissertation. Örebro University.

Strand, R. (2013). The chief officer of corporate social responsibility: A study of its presence in top management teams. Journal of Business Ethics, 112(4), 721-734.

Strand, R. (2014). Strategic leadership of corporate sustainability. Journal of Business Ethics, 123(4), 687-706.

Strand, R., Freeman, R. E., \& Hockerts, K. (2015). Corporate social responsibility and sustainability in scandinavia: An overview. Journal of Business Ethics, 127(1), 1-15.

Thornton, P. H. (2002). The rise of the corporation in a craft industry: Conflict and conformity in institutional logics. The Academy of Management Journal, 45(1), 81-101.

Ulrich, D., Younger, J., Brockbank, W., \& Ulrich, M. D. (2013). The state of the HR profession. Human Resource Management, 52(3), 457-471.

Vallentin, S., \& Spence, L. J. (2017). Strategic CSR: Ambitions and critiques. In A. Rasche, M. Morsing, \& J. Moon (Eds.), Corporate social responsibility: Strategy (pp. 63-85). Cambridge University Press.

van Maanen, J. (1979). The fact of fiction in organizational ethnography. Administrative Science Quarterly, 24(4), 539-550.
Waddell, D., \& Mallen, D. (2001). Quality managers: Beyond 2000? Total Quality Management, 12(3), 373-384.

Weinreb Group. (2011). CSO back story: How chief sustainability officers reached the $C$-suite. Weinreb Group. Retrived December 21st, 2021, from https://weinrebgroup.com/wp-content/uploads/2011/ 09/CSO-Back-Story-by-Weinreb-Group.pdf.

Weinreb Group. (2014). CSO back story II: The evolution of the chief sustainability officer. Weinreb Group. Retrieved December, 21st, 2021, from https://weinrebgroup.com/wp-content/uploads/2018/ 07/CSO-Back-Story-II.pdf.

Weinreb Group. (2018). Updated CSO research. Weinreb Group. Retrieved December 21st, 2021, from https://weinrebgroup.com/ cso-update-december-2018/.

Wiengarten, F., Lo, C., \& Lam, J. (2017). How does sustainability leadership affect firm performance? The choices associated with appointing a chief officer of corporate social responsibility. Journal of Business Ethics, 140(3), 477-493.

Windell, K. (2006). Corporate social responsibility under construction: Ideas, translations, and institutional change. Department of Business Studies.

Wright, C., Nyberg, D., \& Grant, D. (2012). "Hippies on the third floor": Climate change, narrative identity and the micro-politics of corporate environmentalism. Organization Studies, 33(11), 1451-1475.

Publisher's Note Springer Nature remains neutral with regard to jurisdictional claims in published maps and institutional affiliations. 